\title{
Peritonite infecciosa felina: aspectos clínico-patológicos em um gato doméstico (Felis catus)
}

\section{Feline infectious peritonitis: clinical and pathologic features in a domestic feline (Felis catus)}

\author{
Bianca Chiganer Cramer Ribeiro, ${ }^{*}$ Rogério Tortelly, ** Eulógio Carlos Queiroz de Carvalho**
}

\begin{abstract}
Resumo
Um felino doméstico (Felis catus), sem raça definida, fêmea, 2 anos de idade, que vivia no Rio de Janeiro (RJ), apresentou histórico, anamnese e resultados dos exames clínico e complementares que, comparados com a literatura especializada, sugeriram a forma efusiva da peritonite infecciosa felina (PIF). A histopatologia de fragmentos de órgãos coletados durante a necrópsia confirmou a suspeita clínica, mas infecção concomitante pelo vírus da leucemia felina não foi observada.
\end{abstract}

Palavras-chave: peritonite; felino; coronavírus.

A peritonite infecciosa felina (PIF) é uma enfermidade progressiva, fatal e imunologicamente mediada, (Corrêa, Corrêa, 1992 ; Evermann et al., 1995; Weiss, 1991,1994,1998; Wolf, 1997b) que acomete felinos domésticos (Felis catus) e selvagens. (Corrêa, Corrêa, 1992 ; Evermann et al., 1995 ; Weiss, 1994,1998). Seu agente etiológico é um coronavírus felino (FCoV), o vírus da peritonite infecciosa felina (FIPV). (Evermann et al., 1995 ; Weiss, 1991, 1994, 1995 ; Wolf, 1997a) ; Addie, 1994 ; August, 1992 ; Foley, 1997 ; Nelson, 1994 ; Pedersen, 1995 ; Sparkes, 1991). Costuma acometer gatos de 6 meses a 5 anos de idade,(Corrêa, Corrêa, 1992; Weiss, 1994 ; Wolf, 1997a) sendo a incidência maior entre 6 meses e 2 anos (Corrêa, Corrêa, 1992; Weiss, 1991,1994, 1998; Grahn, 1991) voltando a aumentar após 14 anos de idade. (Weiss, 1994, 1998; Wolf, 1997a) A transmissão provavelmente ocorre pela ingestão do vírus, através de aerossóis (Weiss, 1994, 1998 ; Addie, 1994 ; Nelson, 1994) ou, ainda não comprovado, por via transplacentária(Weiss, 1994, 1998; Addie, 1994). Suas duas formas clínicas são: efusiva e não-efusiva (Corrêa, Corrêa, 1992 ; Evermann et al., 1995 ; Weiss, 1991, 1994, 1998 ; Wolf, 1997a ; August, 1992 ; Nelson, 1994 ; Pedersen, 1995 ; Sparkes, 1991 ; Grahn, 1991 ; Harvey et al., 1996). Muitos gatos com PIF são concomitantemente infectados pelo vírus da leucemia felina (FeLV), um retrovírus imunossupressivo que compromete severamente a imunidade celular, necessária para a resistência à PIF. (Weiss, 1994-98; Pedersen, 1995). O objetivo deste trabalho é relatar uma enfermidade progressiva observada em um felino doméstico, na cidade do Rio de Janeiro, RJ, cujo histórico, anamnese e resultados dos exames clínico e complementares foram comparados com a literatura especializada com fins de diagnóstico (PIF), inclusive diferencial (leucemia felina). O felino em questão, sem raça definida, fêmea, 2 anos de idade, apresentava hiporexia, apatia e emagrecimento. Durante exame clínico, a palpação abdominal re- velou tumoração na região mesogástrica. Exames complementares revelaram: linfoadenopatia mesentérica e ascite (ultrasonografia abdominal); neutrofilia absoluta com desvio à esquerda regenerativo, linfopenia absoluta e hiperproteinemia (hemograma completo); hiperproteinemia e hiperglobulinemia (bioquímica sérica); sorologia para coronavírus positiva (método "enzyme-linked immunosorbent assay" - ELISA). Após eutanásia, o animal foi submetido à necrópsia e fragmentos de seus órgãos foram enviados para exame histopatológico. A necrópsia e a histopatologia revelaram uma peritonite serofibrinosa, com acentuada deposição de fibrina na superfície do baço (figura 1), fígado, intestinos, mesentério, além do aspecto similar observado no pericárdio e na pleura visceral. Os linfonodos mesentéricos, que apresentavam aumento de volume, o fígado (figura 2) e os rins (figura 3) exibiam também

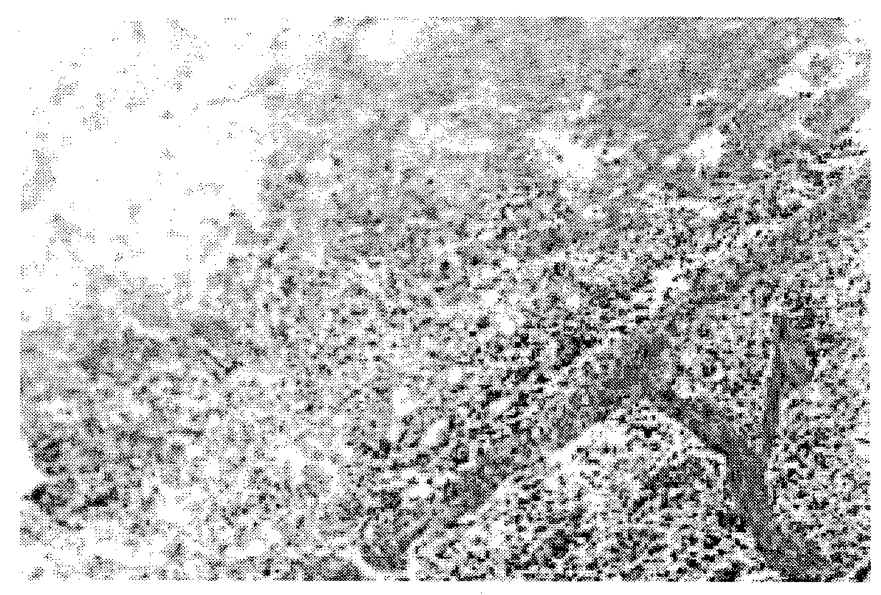

Figura 1: PIF: Baço de felino. Exsudato sero-fibrinoso da cápsula esplênica. Periesplenite sero-fibrinosa. HxE, $100 \mathrm{X}$.

\footnotetext{
* Médica veterinária autônoma, Rio de Janeiro, RJ.

** Professores do Serviço de Patologia Veterinária Jefferson Andrade dos Santos/MPT/UFF.
} 


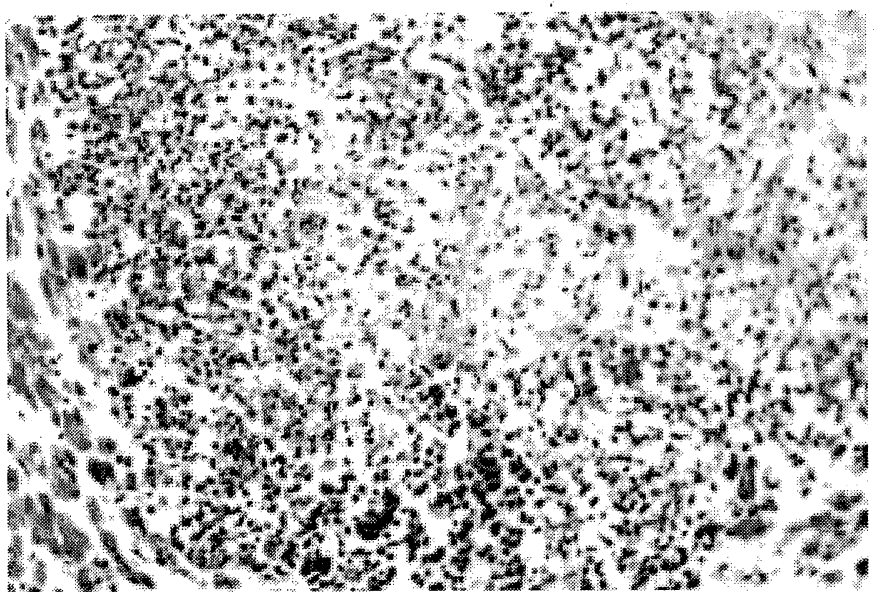

Figura 2: PIF: Fígado de felino. Granuloma com necrose central. Hepatite granulomatosa. HxE, 200X.

lesões multifocais esbranquiçadas de șeus parênquimas, representadas microscopicamente por granulomas comumente centralizados por necrose, envoltos por exsudato predominantemente mononuclear. Focos de vasculite foram observados em lesões de linfonodos. O exame histológico das alterações das serosas era caracterizado por um infiltrado linfoplasmocitário ao lado da presença de fibrina. Concluiuse, através da comparação do histórico, anamnese e resulta-

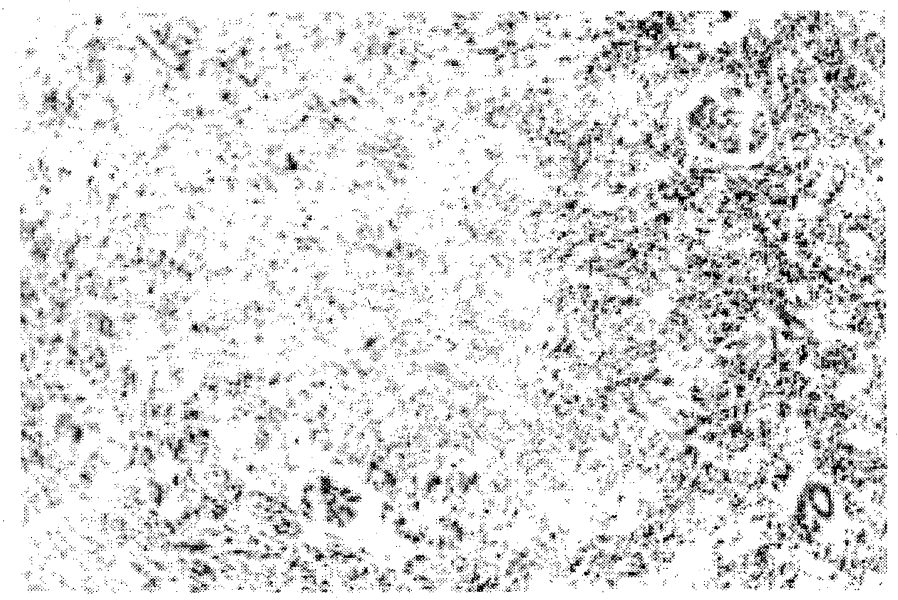

Figura 3: PIF: Rim de felino. Granuloma com necrose central. Nefrite granulomatosa. HXE, $100 \mathrm{X}$.

dos dos exames clínico e complementares referentes ao felino com a bibliografia consultada, que a enfermidade em questão era a forma efusiva da PIF, o que foi confirmado através da histopatologia. Já que não foi realizada sorologia para o FeLV, a conclusão de que a leucemia felina não era concomitante à PIF foi obtida através da análise histopatológica de fragmentos de órgãos coletados durante a necrópsia.

\section{Abstract}

A domestic feline, no breed, female, 2 years old, in Rio de Janeiro (RJ) had presented history, clinical signs and results of complementary tests that have been compared to specific literature and suggested the effusive form of feline infectious peritonitis (FIP). Histology of visceral fragments collected during necropsy has confirmed FIP, but co-infection with feline leukemia virus was not observed.

Keywords: peritonitis; feline; coronavirus.

\section{Referências bibliográficas}

CORRÊA, W. M., Corrêa, C. N. M. Enfermidades infecciosas dos mamíferos domésticos. 2. ed. Rio de Janeiro: MEDSI, 1992. 843 p. Cap. 57: Peritonite infecciosa dos gatos, p. 569-573.

EVERMANN, J. F., HENRY, C. J., MARKS, S. L Feline infectious pentonitis. JAVMA, Schaumburg, v. 206, n. 8, p. 1130-1134, abr. 1995.

WEISS, R. C. The diagnosis and clinical management of feline infectious peritonitis. Veterinary Medicine, v. 86, n. 3, p. 308319, mar. 1991.

Feline infectious peritonitis and other coronaviruses. In: SHERDING, R.G. The Cat: diseases and clinical management. 2. ed. Philadelphia: W. B. Saunders, 1994. 2 v. V. 1. Cap. 13, p. 449-477.

Feline infectious peritonitis and pleuritis. In: Aiello, $\mathrm{S}$. E. The Merck Veterinary Manual. 8. ed. Philadelphia: National Publishing, 1998. 2305 p. p. 551-555.

WOLF, A. M. Feline infectious peritonitis, Part 1. Feline Practice, California, v. 25, n. 2, p. 26-29, mar./abr. 1997.

WOLF, A. M. Feline infectious peritonitis, Part 2. Feline Practice, California, v. 25, n. 3, p. 24-28, maio/jun. 1997.

ADDIE, D. D. Feline coronavirus in the multicat household. Feline Practice, California, v. 22, n. 3, p. 32-39, maio/jun. 1994.
August, J. R. Moléstias Viráis Felinas. In: Ettinger, S. J. Tratado de Medicina Interna Veterinária. 3. ed. São Paulo: Manole, 1992. 4 v. V. 1. Cap 48, p. 327-356.

Foley, J. E., Poland, A., Carlson, J., Pedersen, N. C. Risk factors for feline infectious peritonitis among cats in multiple-cat environments with endemic feline enteric coronavirus. JAVMA, Schaumburg, v. 210, n. 9, p. 1313-1318, maio 1997.

NELSON, R. W., Couto, C. G. Fundamentos de Medicina Interna de Pequenos Animais. Rio de Janeiro : Guanabara Koogan, 1994. 737 p. Cap. 98: Peritonite Infecciosa Felina, p. 721-722.

PEDERSEN, N. C. An overview of feline enteric coronavirus and infectious peritonitis virus infecction. Feline Practice, California, v. 23, n. 3, p. 7-20, maio/jun. 1995.

SPARKES, A. H., Gruffydd-Jones, T. J., Harbour, D. A. Feline infectious peritonitis: a review of clinico-pathological changes in 65 cases, and a critical assessment of their diagnostical value. The Veterinary Record, London, v. 129, p. 209-212, set. 1991.

GRAHN, B. H. The feline coronavirus infections: feline enteric peritonitis and feline coronavirus enteritis. Veterinary Medicine, p. 376-393, abr. 1991.

HARVEY, C. J., LOPEZ, J. W., HENDRICK, M. J. An uncommon intestinal manifestation of feline infectious pentonitis: 26 cases (19861993). JAVMA, Schaumburg, v. 209, n. 6, p. 1117-1120, set. 1996. 